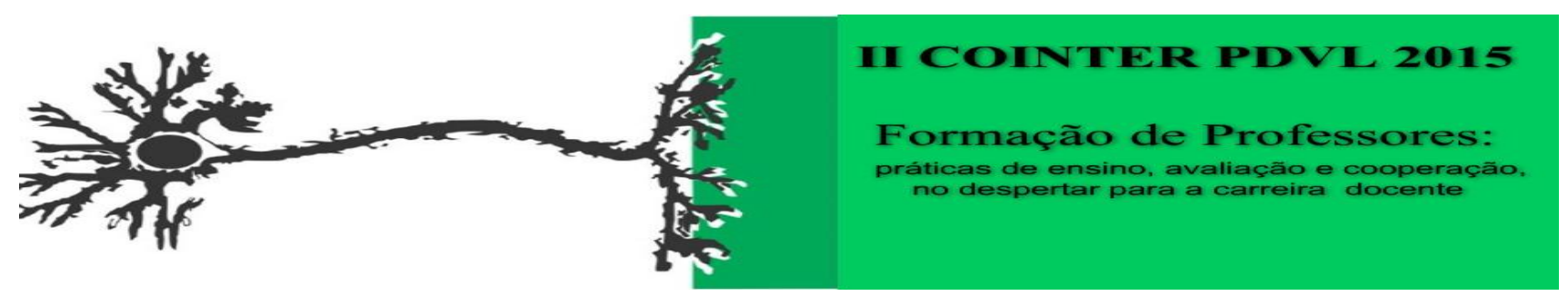

\title{
LUZ EM AÇÃO - EXPERIMENTOS DE ÓPTICA EM SALA DE AULA
}

Apresentação: Relato de Experiência

\section{Marina Nunes de Oliveira ${ }^{1}$; Zaidilma dos Santos Santana ${ }^{2}$; Indira dos Santos Alves ${ }^{3}$; Albertina Marília Alves Guedes ${ }^{4}$}

\section{Introdução}

De acordo com estudiosos da área de Física uma das estratégias pedagógicas que podem ser utilizadas por professores em busca de minimizar o índice reprovação na disciplina de Física é a realização de Experimentos Físicos. Para Araújo e Abid (2003), esses experimentos podem despertar o interesse e curiosidade de estudantes em aprender Física. Para Gaspar e Monteiro (2005), atividades experimentais permitem aos alunos o contato com o objeto concreto e, por sua vez, tiraos da zona de equilíbrio cognitivo, colocando-os em zona de conflito, e, consequentemente viabiliza ao estudante construir um novo conhecimento (PIAGET, 1996).

Outro aspecto relevante para a realização desses experimentos refere-se ao fato de que o ano de 2015 é considerado o Ano Internacional da Luz. De acordo com UNESCO (2015, p. 7), a temática "Luz" é importante visto ser muito utilizada em qualquer nível de trabalho e/ou tecnologia a qual tem impulsionado grandemente em todas as dimensões do desenvolvimento humano, assim sendo, essa "é uma oportunidade única para se inspirar, para se educar e para se unir em escala mundial". O Ano Internacional da Luz é uma iniciativa mundial que visa destacar a importância da luz e das tecnologias ópticas na vida dos cidadãos, bem como no futuro e no desenvolvimento das sociedades de todo o mundo. Por isso, foi considerado importante trazer essa temática para a sala de aula e discutir com os alunos ideias, tais como: sustentabilidade, energia, saúde, educação, meio ambiente, dentre outros.

\section{Relato de Experiência}

Esse trabalho refere-se a um Relato de Experiência sobre a realização de experimentos físicos. Foi vivenciada com 10 alunos de uma turma do $1^{\circ}$ ano do Ensino Médio de uma escola pública localizada no município de Petrolina-PE. Essa experiência relaciona-se ao aspecto de que apesar dos conteúdos de "óptica" e "luz" estar presente no cotidiano dos alunos, percebe-se que os estudantes tem dificuldades em compreender e aprender sobre esses conteúdos. Desse modo, o

\footnotetext{
${ }^{1}$ Estudante do Curso de Licenciatura em Física do IF Sertão PE. E-mail: marina.mno@hotmail.com

${ }^{2}$ Estudante do Curso de Licenciatura em Física do IF Sertão PE. E-mail: zaidilmass@gmail.com

${ }^{3}$ Estudante do Curso de Licenciatura em Física do IF Sertão PE. E-mail: indira.alves.2012@hotmail.com

${ }^{4}$ Professora do Curso de Licenciatura em Física IF Sertão PE. E-mail: albertinamarilia@hotmail.com
} 
problema que norteou esse trabalho foi: Como é possível despertar o interesse e motivação de estudantes para a aprendizagem de conteúdos de Física sobre "óptica” e "luz".

Objetivando verificar os conhecimentos prévios dos alunos acerca da temática "óptica", inicialmente, foi realizada uma conversa com os mesmos (AUSUBEL, 1968). Neste momento foi possível saber o que os alunos compreendiam por "óptica". Também foram apresentadas as principais características da "óptica", bem como esclarecer as principais dúvidas dos alunos. Em seguida, foram selecionados alguns experimentos que abordavam as temáticas: reflexão, decomposição da luz, propagação da luz, espelhos planos, côncavos e convexos. Todos os materiais selecionados e utilizados nos experimentos eram materiais de baixo custo e/ou reciclados. Para a execução dos experimentos teve-se o cuidado em elaborar um planejamento prévio o qual descreveu cada etapa dos experimentos, bem como o objetivo almejado em cada etapa do referido planejamento.

Para a realização dos experimentos foi organizado quatro subgrupos. Em seguida, os alunos foram orientados para a execução dos experimentos. Após cada subgrupo finalizar a montagem e execução dos experimentos foi solicitado que cada subgrupo socializasse em sala de aula o que aprenderam com a realização desta atividade.

\section{Considerações Finais}

A partir dessa experiência percebe-se que a realização de atividades experimentais em sala de aula podem facilitar a aprendizagem e despertar o interesse e curiosidade dos alunos sobre os conteúdos de Física mediante o uso de materiais de baixo custo e/ou reciclados.

\section{Referências}

ABID, M. L; ARAÚJO, M. S. Atividades experimentais no ensino da Física: diferentes enfoques, diferentes finalidades. Revista Brasileira de Ensino de Física, v. 25, nº 2, p. 176-194, 2003.

GASPAR, A; MONTEIRO, I. C. C. Atividades experimentais de demonstrações em sala de aula: uma análise segundo o referencial da teoria de Vygotsky. Revista Investigações em Ensino de Ciências. v. 10, n. 2, p. 227-254, 2005.

UNESCO, 2015. Ano Internacional da Luz. Disponível em: <http://www.unesco.org/new/ pt/ brasilia/about-this-office/prizes-and-celebrations/2015>. Acesso em: 22 Out. 2015.

PIAGET, J. A equilibração das estruturas cognitivas: problema central do desenvolvimento. Rio de Janeiro, 1996.

AUSUBEL, D. P. Educational psychology: a cognitive view. Nueva York: Holt, 1968. 